\title{
EFFECT OF MAGNEVIST CONJUGATED DENDRIMER ON Bax/Bcl2 GENE EXPRESSION LEVELS IN MCF-7 CANCER CELLS
}

\author{
Sara Fattah ${ }^{1}$, BaharJavani ${ }^{1}$, MostafaSaffari ${ }^{1}$, SeyedAtaollah Sadat Shandiz ${ }^{3}$ and Mehdi \\ ShafieeArdestani ${ }^{2, *}$
}

\footnotetext{
${ }^{1}$ Islamic Azad University Pharmaceutical Sciences Branch (IAUPS), No 99, Yakhchal,Gholhak,ShariatiTehran ,Iran

${ }^{2}$ Department of Radiopharmacy, Faculty of Pharmacy, Tehran University of Medical Sciences, Tehran, Iran

${ }^{3}$ Young Researchers and Elite Club, East Tehran Branch, Islamic Azad University, Tehran, Iran
}

Received - March 29, 2016; Revision - April 08, 2016; Accepted - June 28, 2016

Available Online - June 30, 2016

DOI: http://dx.doi.org/10.18006/2016.4(4).440.447

\begin{abstract}
KEYWORDS
Magnevist conjugated

dendrimer

Real-time PCR

MCF-7

Apoptosis

Corona protein

ABSTRACT

In recent years, investigating pharmacogenetics and effects of corona protein nanomaterial in biological applications has been seriously considered for the treatment of human diseases. In this study, the mechanism of apoptosis induced by Magnevist conjugated dendrimer was investigated to compare Magnevist as a contrasting agent on MCF-7 cells. Cytotoxicity effects of new Magnevist conjugated dendrimer was evaluated by using MTT assay. Also, In order to demonstrate the effect of drugs on the apoptosis, a quantitative method real-time PCR was used. The interaction of plasma proteins was investigated by Magnevist conjugated dendrimer compared with Magnevist using SDS-PAGE technique to determine the fate of nanoparticles. Result of study revealed that it quite significantly affects Bax and increasing apoptosis. Its effect on $\mathrm{Bcl} 2$ is more than net gadopentetic acid and almost equivalent to the effect of dendrimer alone. In fact, a significant increase was observed in Bax compared to the control group, and no significant effect was observed on BCL2 gene. Also, corona protein was investigated and the protein with weight less than $70 \mathrm{kDa}$ was observed around a nanoparticle that seems albumin protein with a molecular weight of $67 \mathrm{kDa}$. Conducted study revealed the acceptable therapeutic effect of Magnevist conjugated dendrimer and it was comparable with in vitro Magnevist model of breast cancer. Therefore, the use of the denderimer can be effective on increasing expression of some proapoptoticgenes and provided a new perspective in clinical diagnostic.
\end{abstract}

* Corresponding author

E-mail: shafieeardestani@gmail.com (Mehdi Shafiee Ardestani)

Peer review under responsibility of Journal of Experimental Biology and Agricultural Sciences.

Production and Hosting by Horizon Publisher (http://publisher.jebas.org/index.html).

All rights reserved.
All the article published by Journal of Experimental Biology and Agricultural Sciences is licensed under a Creative Commons Attribution-NonCommercial 4.0 International License Based on a work at www.jebas.org. 


\section{Introduction}

After cardiovascular diseases, cancer is the second leading cause of death in the United States of America (Abdelhady, 2012). In developing countries men, the most common types of reported cancers are prostate, lung, colorectal cancers, while in women these are breast, lung and colorectal cancers. However, in developed countries this picture slightly changes and the most common types of cancers in men included stomach, lung and liver and in women these are breast, cervical and stomach cancers (Anand et al., 2008). Now in these days, the main focus of cancer research is to search anticancer agents with high safety coefficient and more acceptability rate among patients (Carr et al., 1984; Wray et al., 2005; Deuflhard et al., 1997). Recently, treatment based on the molecular markers/ technique proved very much progressive and showed high specificity against tumor cells. These techniques opened new doors in the field of cancer research and reduced the risk of toxicity (Wang et al., 2008).

In addition, they can be used in combination with chemotherapy or radiation therapy for synergistic anti-cancer activity. Therefore, the targeted treatment has been as a new and promising approach for cancer treatment (Fox, 2000).The phenomenon of apoptosis are playing important role in the cancer management. In this process without damaging the surrounding cells or tissues unwanted, damaged and dangerous cells can be removed. Apoptosis induction is one of the most important methods for destroying cancer cells without complication (Abdelhady, 2012). Cancer cells normally escape from apoptosis; one of the reasons for this is the change in the expression of genes involved in the regulation of this process (Carr et al., 1984).

More anti-cancer agents apply their therapeutic effects by inducing programmed cell death. The Bcl-2 protein can play a vital role in the creation and inhibition of apoptosis in cells. This protein regulates the activity of caspase enzymes in apoptosis pathway. Further, this Bcl-2 protein releases cytochrome $\mathrm{c}$ from mitochondria, which leads to activation of caspase- 9 and then caspase-3. It ultimately leads to the cell suicide (Cree, 2011). Gadolinium-containing drugs could be divided into different types based on ligands binding to them (chelates), the most important are DTPA, HP-DO3, and DTPA-BMA.

These ligands can be linear or cyclic (Klajnert \& Bryszewska, 2001). In theory, cyclic gadolinium chelates are more stable than linear ones. Moreover, these compounds can be ionic or nonionic. Nonionic solutions produce lower osmolarity rate in the solution and hence are more appropriate contrast agents. Now in these days, many researches are actively involved in the design and construction of ligands due to their tight binding to the gadolinium ion. Gadopentetate dimeglumine drug is one of the oldest contrast agents used in MRI. It is approved by American Food and Drug Administration (FAD) and is consumed through injection (Hijazi \& Boulieu, 2002; Milenic et al 2004).

In fact, this compound is composed of N- methyl-glucosamine salt of gadolinium-containing DTPA complex. It is MAGNEVIST $®$ brand and is prepared as a sterile aqueous, a clear, colorless to pale yellow solution for intravenous injections. Dendrimers are spherical hyper branched units that have polymer branches with different size. They also have symmetrical spherical shape and a lot of spaces in their structure, in which drugs can be safely placed (Milenic et al., 2004). Each of the dendrimer branches is called dendron. Ideally a dendrimer is divided into three parts including core, inner shell and the outer shell (Mansfield \& Pykett, 1978). The synthetized dendrimers should have different capabilities in each of these areas for controlling properties such as solubility, thermal stability and the number of branches. Moreover, they also can have protein or polymer cores (linear, branchedand spherical).

The objective of present study was to investigate the radio pharmacogenetic effects of Magnevist conjugated dendrimer compared with Magnevist on cytotoxicity and the Bcl2. Further, the effects of plasma protein aggregation or binding on the Magnevist conjugated dendrimer compared with Magnevist protein corona technique was also investigated in the present study.

\section{Materials and Methods}

\subsection{Dendrimer synthesis}

Initially, 2.5 to $3 \mathrm{~mL}$ of liquid polyethylene glycol (600) was taken in the container and it was followed by the addition of $4 \mathrm{~mL}$ of DMSO solvent. Afterwards, $1 \mathrm{~g}$ of DCC (D cyclohexane Hexyl carbo di imide) was added in this solution. Later on, citric acid dendrimer was synthesized with polyethylene glycol core in the first stage and in the end of this dendrimers were functionalized in the presence of DCC using imidazole functional groups. After 5 minutes of this, $1 \mathrm{~mL}$ of citric acid was added in this mixture (Reaction was performed at room temperature) and left it for two hours.

\subsection{Purification}

In purification, synthesized dendrimer were separated from the impurities such as citric acid, and unreacted DCC. In the first step of purification, $5 \mathrm{ml}$ of water was added in this synthesized dendrimer solution, DCC is insoluble in water while the dendrimers are soluble. This mixture was passed through the simple filter paper where dissolved dendrimers passed through the paper while precipitate DCC remained on filter paper. In second step of purification, the mixture passed through sephadex advanced column for the separation of citrus solutions impurities. 
2.3 Adding the dendrimer to the gadopentetic acid drug

In this step, $5 \mathrm{ml}$ of gadopentetic acid (469) mixed with $5 \mathrm{ml}$ of dendrimer (234.5) in a vial and the mixture was sonicated for 10 minutes in sonicator (model KST 7703) and stored at refrigerator.

\subsection{Determine the viability percentage by MTT test assay}

The breast cancer MCF-7 cell line was purchase from pasture institute of Iran. For performing MTT assay, cells were cultured in 96-well cell culture containers containing $\mathrm{RPMI}_{1640}$ medium supplemented by $10 \%$ fetal bovine serum (FBS). Different concentrations of Magnevist conjugated dendrimer $(0,3.125,6.25,12.5,25,50$ and $100 \mu \mathrm{M})$ were prepared and $100 \mathrm{ml}$ of each of pre-made concentrations of gadopentetic acid nanoparticle was added in cultured cells. $100 \mathrm{~mL}$ of MTT $(0.5 \%)$ dye was added in to each cultured well. This was followed by the storing cultural plate in incubator and later on cells were evacuated and $100 \mathrm{~mL}$ of DMSO is added to each plate and the culture container is placed at room temperature for 30 minutes. In the next stage, the absorption rate was measured at $570 \mathrm{~nm}$ using Elisa Reader. The survival rate of Magnevist conjugated dendrimer treated breast cancer cells, was calculated by using following formula:

Cytotoxicity percentage $=1$ - $($ mean absorbance of toxicant treated cells) / (mean absorbance of negative control) $\times 100$

To determine the $50 \%$ lethal dose of Magnevist conjugated dendrimerin MCF-7 cell lines of cancer cells, all information obtained (toxicity amount) from samples and controls were investigated using Pharm-PCS statistical package software and the exact amount of the related $\mathrm{IC}_{50}$ was determined.

\subsection{Identification and estimation of gene expression by PCR}

Initially, $2 \times 10^{6}$ cells were poured into T- 25 flasks and were treated by using different concentrations of Magnevist conjugated dendrimer for 24 hrs. RNA of the selected cells were extracted by a method given by Hahn et al. (2011) in five steps i.e. homogenization, separation, precipitation, washing and re-dissolving of RNA. Cells were separated by using trypsin and PBS at 1100rpm centrifugation. These separated cells were mixed with $1 \mathrm{ml}$ of cold RNA extraction solution, this mixture were homogenized on vertex shaker. Homogenized samples were incubated five minutes at room temperature and $200 \mathrm{ml}$ of chloroform was added in this mixture. These microtubes are now shaken strictly by hand for 15 seconds and stored at room temperature for 5 minutes.

After five minutes, these tubes were centrifuged for 15 minutes at $12000 \mathrm{rpm}$ at $4^{\circ} \mathrm{C}$. Supernatant colorless aqueous solution were separated and collected in other micro tubes. Isopropyl alcohol was added in these tubes supernatant aqueous solution containing tubes and again the samples were centrifuged at $12000 \mathrm{rpm}$ for 15 minutes at $4^{\circ} \mathrm{C}$. Extracted RNA was sediment on the bottom of the tube and the supernatant were emptied. RNA pallets were washed one with $75 \%$ ethanol and dried in the air for 5 to 10 minutes. These RNA pallets were dissolving in DEPC water and stored at $-70^{\circ} \mathrm{C}$. Later, the quantity and purity of the extracted RNA was determined using photo-nanometer (IMPLEN GmbH, Germany). For complementary DNA (cDNA) synthesis, the Revert AidTM First Strand cDNA Synthesis Kit (Fermentas, USA) were used according to protocol. The reaction mixture contains $1 \mu \mathrm{g}$ of RNA, $5 \mu \mathrm{L}$ reaction buffer, $0.5 \mu \mathrm{L}$ of primer Oligo (dT), 0.5 $\mathrm{mL}$ of randomized hexamer primer, 2-ml deoxynucleotide triphosphate mixture $(10 \mathrm{mM}), 1 \mu \mathrm{l}$ of the enzyme RNase inhibitor (20 units per microliter), $1 \mu \mathrm{l}$ reverse transcriptase MMulV and $\mathrm{H}_{2} \mathrm{O}$ DEPC (to a final volume of $20 \mu \mathrm{L}$ ). The PCR reaction was performed using iCycler Thermal Cycler (BioRad, Hercules, CA, USA).

\subsection{Primer Design}

In order to design primers, the cDNA sequences of genes were initially obtained from GenBank and then best gene region was determined for these primers using Primer express software v.3.0 (Applied Biosystems, USA). To ensure the accuracy of the primer sequences and the absence of their non-specific binding to sequences in other parts of the genome, primers were blasted (http://www.ncbi.nlm.nih.gov/blast) (Table 1).

Table 1 Primers used in real time PCR reactions for present study.

\begin{tabular}{|l|l|}
\hline Gene of interest & Primer sequence \\
\hline$B c l-2$ & Forward: 5'- TGTGGATGACTGAGTACCTGAACC-3' \\
& Reverse: 5'-CAGCCAGGAGAAATCAAACAGAG-3' \\
\hline Bax & $\begin{array}{l}\text { Forward: 5'-TTGCTTCAGGGTTTCATCCAG-3' } \\
\text { Reverse: 5'-AGCTTCTTGGTGGACGCATC-3' }\end{array}$ \\
\hline GAPDH & Forward: 5'-CGTCTGCCCTATCAACTTTCG-3' \\
& Reverse: 5'-CGTTTCTCAGGCTCCCTCT-3' \\
\hline
\end{tabular}


Real Time PCR method was carried out in 3 steps in first step, denaturation of cDNA molecules and activation of the polymerase enzyme was done as follows: $95^{\circ} \mathrm{C}$ for 10 minutes; while in the second stage at $95{ }^{\circ} \mathrm{C}$ for 15 seconds and $60{ }^{\circ} \mathrm{C}$ for 1 minute, 40 consecutive cycles was carried out, and in the final stage for drawing melting curve as $95^{\circ} \mathrm{C}$ for 15 seconds, $60^{\circ} \mathrm{C}$ for 30 seconds $95^{\circ} \mathrm{C}$ for 15 seconds.

Real-time PCR reactions were performed in a final volume of $20 \mathrm{ml}$ for triplet repeats. The combination of each reaction contains $10 \mu \mathrm{l}$ of SYBR-Green PCR Master Mix (Applied Biosystems, Warrington, UK), $1 \mu \mathrm{l}$ of reverse and forward 400 $\mathrm{nM}$ primers specific for each gene, $5 \mu \mathrm{l}$ of cDNA (300 mg) and the rest distilled water were added until the final volume of 20 $\mathrm{ml}$ was obtained.

PCR amplification curves were plotted for each reaction. Data analysis was performed by comparing the threshold cycle. In this study, the ratio of the target gene (Bax, Bcl2) to the reference gene $(G A P D H)$ was calculated using the formula $\Delta \Delta \mathrm{Ct}$ through $2^{-\Delta \Delta \mathrm{Ct}}$. The calculation formula is as follows:

$\Delta \mathrm{Ct}=\mathrm{Ct}$ target-Ct reference

$\Delta \Delta \mathrm{Ct}=\Delta \mathrm{Ct}$ test sample $-\Delta \mathrm{Ct}$ control sample

Relative expression: $2^{-\Delta \Delta \mathrm{Ct}}$

\subsection{Statistical analysis of data}

Dicomwork, Matlab and Excel were used for statistical analysis of data and the calculation of T1, T2. Micro Dicom also was used to observe the MR images. To quantitatively compare data, SPSS software and Post hoc Tukey test were used. And if the data were compared in group, one way ANOVA test was used.

\subsection{MTT assay}

In order to evaluate the toxicity effects of samples, various dilutions were prepared and transferred to each well 96-well plates. Afterwards, MTT testing phases were read with an ELISA reader (Figure 1).

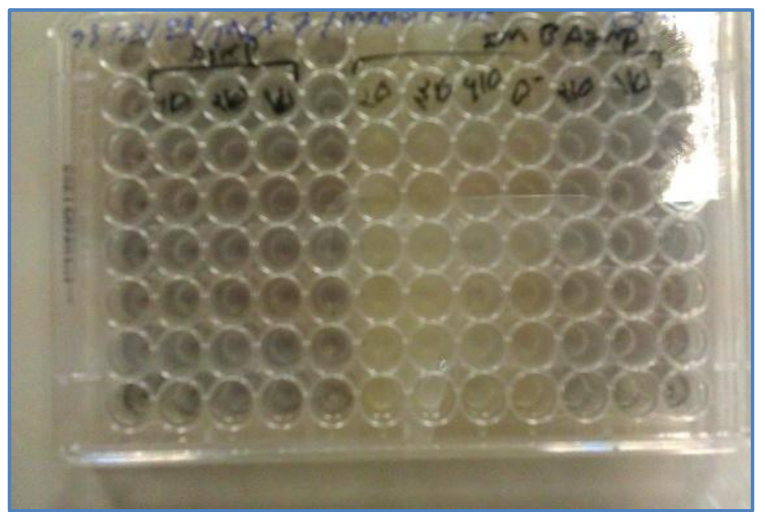

Figure 1 Assay of Cytotoxicity of Magnevist conjugated dendrimeron MCF-7 cells by MTT assay along with ELISA reader

MTT assay test was used to evaluate the survival rate of MCF7 cells against different concentrations of Magnevist conjugated dendrimer. In control $100 \%$ of the cells are alive and cell viability rate is gradually reduced by increasing the dose of Magnevist conjugated dendrimeras (Figure1). A significant toxicity was observed at the increasing of concentrations. With increasing the concentration of Magnevistconjugated dendrimer a significant gradual reduction in the viability of cells was reported. A significant effect in the toxicity level was reported in the concentration range started from 6.5 to 50 , dose above these level are not significantly differ from each other's $(p<0.01)$. As is clear from $\mathrm{IC}_{50}$, proper concentration level was $68.81 \mu \mathrm{M}$ from this study.

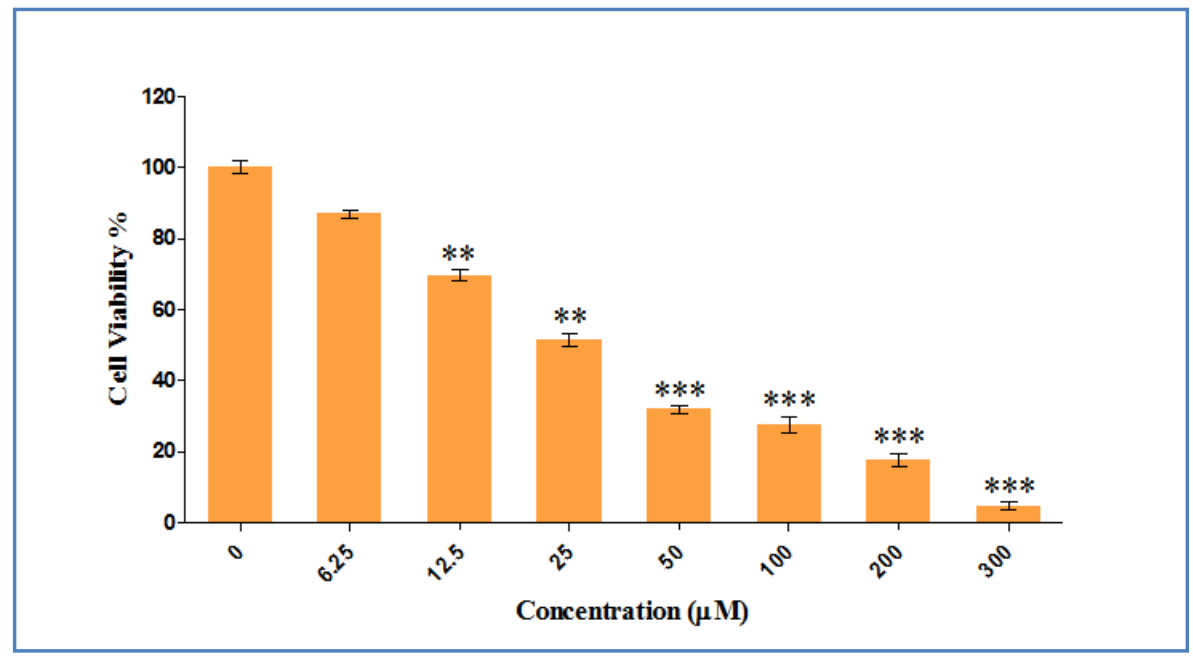

Figure 2 Survival percentages of MCF7 cells against different concentrations of Magnevist conjugated dendrimer within 24 hours 


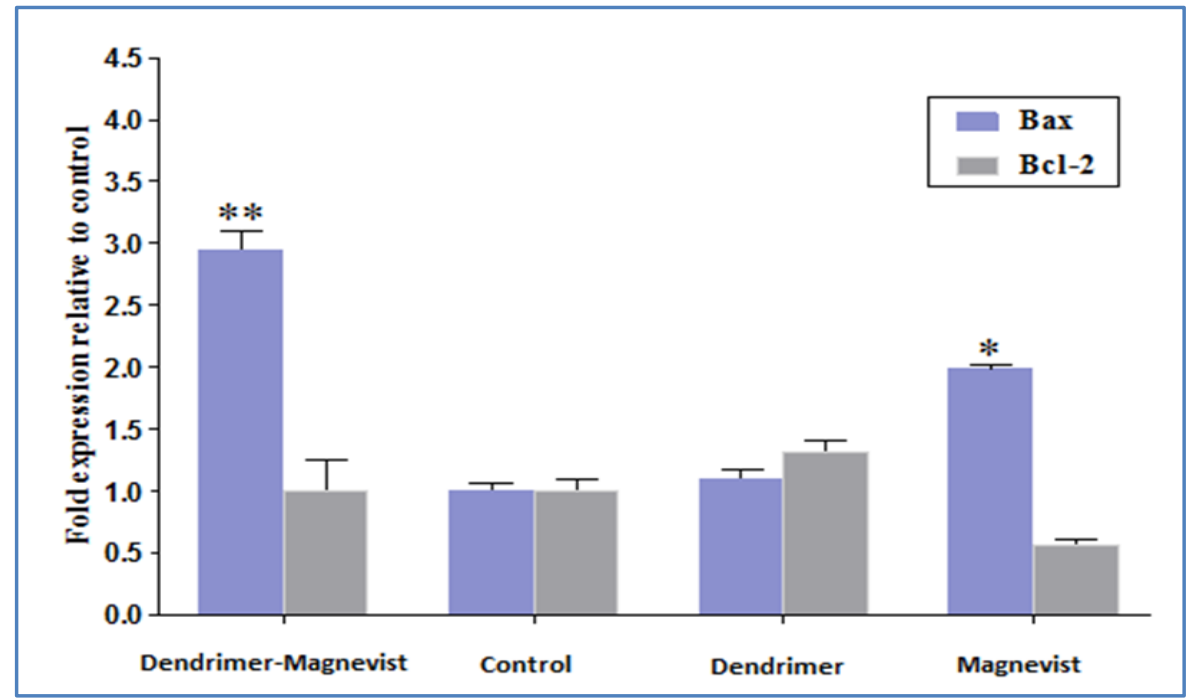

Figure 3 Curve of gene expression changes in MCF7 cell lines with Dendrimer, the Magnevist conjugated dendrimer and Magnevist alone after 24 hours $(*: \mathrm{P} \leq 0.05, * * \mathrm{P} \leq 0.01)$. Comparisons are made for each gene compared with the same gene in the control group

\subsection{Real time PCR}

The effect of Magnevist conjugated dendrimer was investigated and compared it with pure Magnevist alone on apoptosis gene expression. A significant result was observed regarding the effect of the Magnevist conjugated dendrimeron, however such result was not reported for $\mathrm{Bax}$ and $\mathrm{Bcl} 2$.The impact of dendrimers on the $\mathrm{Bax}$ and $\mathrm{Bcl} 2$ genes was not significant but the expression of these gene were increased at some level (In this study best effect showing treatment was used for testing effect but these effect may change with changing concentration). Further, Gadopentetic acid nanoparticle (gadopentetic acid and dendrimer) affect the expression of on Bax and $\mathrm{Bcl} 2$ genes and its effect on Bax gene was higher than the total effect of dendrimers and gadopentetic acid. In fact, it affects Bax quite significantly and increases apoptosis. Further, its effect on $\mathrm{Bcl} 2$ gene is more than the impact of pure gadopentetic acid and is approximately equivalent to the effect of dendrimer alone. In fact, compared to the control group, a significant increase was observed in Bax compared with the control group and there was little impact on $\mathrm{Bcl} 2$.

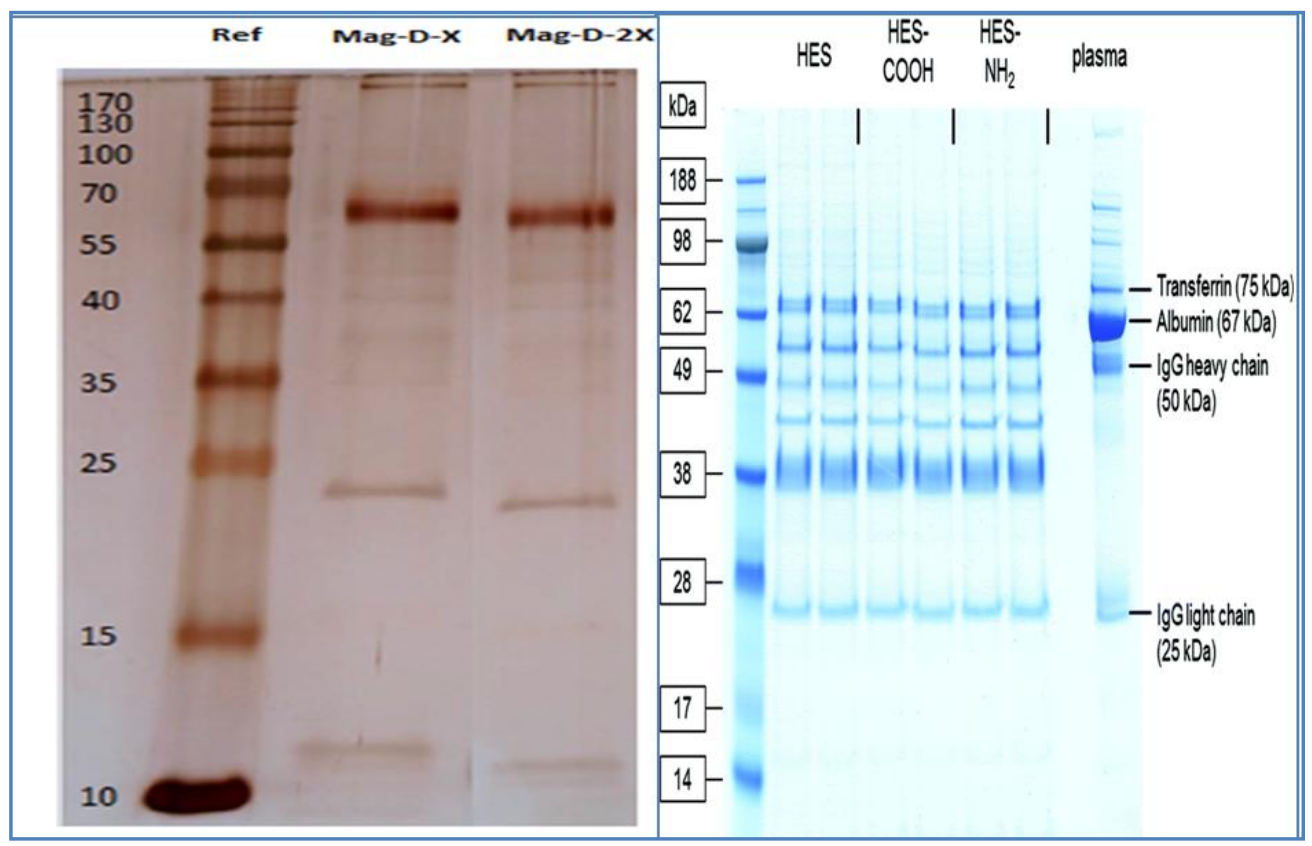

Figure 4 Results of corona protein, protein identification based on the size specified in gel electrophoresis 
3.3 Identification of corona protein

A protein weighing less than $70 \mathrm{kDa}$, and another protein weighting $22 \mathrm{kDa}$ were seen in the plasma serum, which is attached to the nanoparticle. As shown in Figure 4, it seems that the albumin protein with a molecular weight of $67 \mathrm{kDa}$ is the protein less than $70 \mathrm{kDa}$ around gadopentetic acid nanoparticle.

\section{Discussions}

Considering the fact many genetic changes are needed in order to cause cancer. Further, there are many cancers which are hereditary, in such cases a strong possibility of tumor development arises even after the treatment or surgery (Hahn et al., 2011). Result of study revealed that Magnevist conjugated dendrimer have concentration and time dependent killing effect on MCF-7 cancer cells. Further, these dendrimer inhibited the expression of mRNA and anti-apoptotic gene of $\mathrm{Bcl}-2$ while these nanoparticls increased the expression of Bax and this express was significantly higher than the individual exposure of Magnevist drug. Clearly, recognizing the expression pattern importance of genes involved in apoptosis is very important in response to metastatic activity of anticancer drugs. The results of this study show significant therapeutic use of drug loaded on dendrimers against the breast cancer cells. According to these investigations, the clinical studies on the animal and human models are necessary to confirm the effect of gadopentetic acid and Magnevist conjugated on dendrimer. Previous studies showed the in vitro acceptable effect of gadopentetic acid loaded on the dendrimer model on breast cancer as compared to the normal cell.

Therefore, the use of Magnevist (as loaded on the dendrimer) can be effective on the expression of certain apoptotic genes. Based on this study and previous studies, it can be conclude that nanogadopentetic acid compound has powerful anticancer effects on cancer cells and derivatives of this compound could play an important role in treating these types of cancers in the future. So if the clinical process of the drug is approved, the Magnevist conjugated on dendrimer can be applied in a clinical setting for patients with breast cancer in the future. The dendrimer used in this study is composed of a PEG core and two surrounding citric acids and compared with other dendrimers, has unique features. The most prominent of which is biodegradable. In most of synthesized dendrimers, interaction of dendrimer positive charges with the negatively charged cell membrane as a result of the destructed membrane causes hole formation and the lysis of dendrimers cell, which in biological systems cause toxicity, some of which include cytotoxicity, blood and hemolytic toxicity (Kobayashi \& Brechbiel, 2004).There are two overall strategies to reduce the toxicity of dendrimers i.e. first is to design and synthesis of biodegradable dendrimers using biodegradable core and branched units or intermediate metabolic pathways and second is engineering the molecular level, which is done by acetylation of the, PEGylation and carbohydration of molecules (Weinmann et al., 1984.)
The PEG was used at the core of the dendrimer (molecular surface engineering) and its surrounding units are citric acid (Krebs cycle intermediates) (First Strategy). Therefore, the resulting dendrimer is a biodegradable dendrimer and has no significant toxicity. This dendrimer has a negative charge; therefore, it doesn't interact with the negatively charged cell surface and does not destroy the cell membrane. It also has a lot pores for the purpose of drug loading (Fox, 2000). In this study, lower doses of the drug were exposed to the dendrimer; therefore, the drug loading was considered to be 100 percent (Anand et al., 2008). Nanostructures with hydrophilic surface smaller than100 $\mathrm{nm}$ are mostly capable to escape from their molecular phagocytic system. Hydrophobic nanoparticles are quickly picked up by the RES organs. Thus, hydrophilic particles remain more time in the circulation and are picked up to a lesser extent by the liver (Gensel et al., 1990; Franc \& Kakkar, 2009).

The results of this study show positive effects of conjugating the Magnevist on the dendrimer, which ultimately increases the quality of the drug delivery and improves anti-tumor effects of the compound. Present study also shows that Magnevist conjugated dendrimer compared with the gadopentetic acid drug alone, more inhibited anti-apoptotic Bcl-2 gene expression and increased gene expression of Bax genes over time. Different studies revealed that $B c l-2$ gene plays an important role in cancer development. It was reported that Bcl2 gene expression increased the possibilities in $70 \%$ women breast cancer. Also, in preclinical models of prostate cancer Inhibition of $\mathrm{Bcl} 2$ over expression can be associated with apoptosis of cancer cells (Tan et al., 2006). Bcl2 gene product plays a role in inducing growth, survival and inhibition of programmed cell death. While Bax protein induces programmed cell death in cells and its performance is unlike Bcl-2 protein. Bcl-2 and Bax proteins form homodimer and heterodimer structures.

These two proteins are related factors that regulate programmed cell death process (Sakakura et al., 1997). The effect of gadolinium in inducing the apoptosis macrophage was investigated by Mizgerd et al. (1996), according to this 10 minutes making cells subject to gadolinium, significantly induces cell death through the induction of the apoptosis mechanism up to 24 hours (Mizgerd et al., 1996). Further, Greisberg et al. (2001) described that gadodiamide increases the production of proteoglycans, decreases the cell birth and induces apoptosis in chondrocyte. Greisberg et al. (2001) investigated the effect of short term placement of chondrocyte to gadolinium. The cell growth was reduced while exposing to gadolinium (in a dose-dependent manner) and chondrocyte apoptosis was also induced in a dose-dependent manner (Greisberg et al., 2001). Salakou et al. (2007) conducted study on patients with myasthenia gravis underwent cystectomy, Bcl2 ratio to Bax was measured in patients with different disease classifications. It was concluded that if this ratio is less than 1 , it is considered a good marker for caspase activation and apoptosis process adjustment (Salakou et al., 2007). In another study Chiu \& Su (2009) studied the effect of curcumin 
on MDA-MB-231cancer cells. The study showed that molecular mechanisms of curcumin inhibits the generation of MDA-MB-231 through increased expression of p21, an increase of $\mathrm{Bcl} 2$ ratio to $\operatorname{Bax}$ and subsequent apoptosis induction. And this mechanism can create therapeutic potential of curcumin for breast cancer cells.

\section{Conclusion}

Present study confirmed the anti-cancer effects of Magnevist conjugated dendrimer. Further, it is needed to study its impact on the human and animal model. Considering the anti-cancer properties of the samples presented in this study, it is recommended to study the anticancer effects in proteome level of breast cancer cell lines for further exploration. With more extensive knowledge of the properties of nanoparticles, size, shape, surface structure, thickness, degree of porosity, chemistry, etc can be selected based on the purpose of this study.

\section{Conflict of interest}

Authors would hereby like to declare that there is no conflict of interests that could possibly arise.

\section{References}

Abdelhady HG (2012) Morphological and Nanomechanical Investigations of Magnevist Nano-encapsulated Dendrimers by Atomic Force Microscopy. The Libyan Journal of Pharmacy \&Clinical Pharmacology 1: 48154. DOI: http://dx.doi.org/10.5542/LJPCP.v1i0.48154.

Anand P, Kunnumakkara AB, Sundaram C, Harikumar KB, Tharakan ST, Lai OS, Sung B, Aggarwal BB (2008) Cancer is a preventable disease that requires major lifestyle changes. Pharmaceutical Research 25: 2097-2116. doi: 10.1007/s11095008-9661-9.

Carr DH, Brown J, Bydder GM, Steiner RE, Weinmann HJ, Speck U, Hall AS, Young IR (1984) Gadolinium-DTPA as a contrast agent in MRI: initial clinical experience in 20 patients. American Journal of Roentgenology143:215-224. DOI: 10.2214/ajr.143.2.215.

Chiu TL, Su CC (2009) Curcumin inhibits proliferation and migration by increasing the $\mathrm{Bax}$ to $\mathrm{Bcl}-2$ ratio and decreasing NF-kappaBp65 expression in breast cancer MDA-MB-231 cells. International Journal of Molecular Medicine. 23: 469475. DOI: 10.3892/ijmm_00000153.

Cree IA (2011) Cancer cell culture: methods and protocols. Humana Press, New York, Pp. 165-169.

Deuflhard P, Seebass M, Stalling D, Beck R, Hege HC (1997) Hyperthermia Treatment Planning in Clinical Cancer Therapy: Modelling, Simulation and Visualization. Preprint SC Pp. 97 26.

Journal of Experimental Biology and Agricultural Sciences http://www.jebas.org
Fox KR (2000) Targeting DNA with triplexes. Current medicinal chemistry 7:17-37. DOI: $10.2174 / 0929867003375506$

Franc G, Kakkar AK (2009) Diels-Alder "Click" Chemistry in Designing Dendritic Macromolecules. Chemistry A European Journal 15:5630-5639. DOI: 10.1002/chem.200900252.

Gensel PG, Johnson NG, Strother PK (1990) Early Land Plant Debris. Palaios 5: 520-547. DOI: 10.2307/3514860.

Greisberg JK, Wolf JM, Wyman J, Zou L, Terek RM (2001) Gadolinium inhibits thymidine incorporation and induces apoptosis in chondrocytes. Journal of Orthopaedic Research 19:797-801.

Hahn MA, Singh AK, Sharma P, Brown SC, Moudgil BM (2011) Nanoparticles as contrast agents for in-vivo bioimaging: current status and future perspectives. Analytical and Bioanalytical Chemistry 399:3-27. DOI: 10.1007/s00216-0104207-5.

Hijazi Y, Boulieu R (2002) Contribution of CYP3A4, CYP2B6, and CYP2C9 isoforms to $\mathrm{N}$-demethylation of ketamine in human liver microsomes. Drug Metabolism and Disposition 30:853-858.

Klajnert B, Bryszewska M (2001) Dendrimers: properties and applications. Acta biochimica polonica 48:199-208.

Kobayashi H, Brechbiel MW (2004) Dendrimer-Based Nanosized MRI Contrast Agents. Current Pharmaceutical Biotechnology 5: 539-549. DOI: 10.2174/1389201043376571.

Mansfield PI, Pykett PG (1978) Momis Human whole body line-scan imaging by NMR. British Journal of Radiology 51:921-922.

Milenic DE, Brady ED, Brechbiel MW (2004) AntibodyTargeted Radiation Cancer Therapy. Nature Reviews Drug Discovery 3: 488-499. doi:10.1038/nrd1413.

Mizgerd JP, Molina RM, Stearns RC, Brain JD, Warner AE (1996) Gadolinium induces macrophage apoptosis. Journal of Leukocyte Biology 59:189-195.

Sakakura C, Sweeney EA, Shirahama T, Igarashi Y, Hakomori S, Tsujimoto H, Imanishi T, Ogaki M, Ohyama T, Yamazaki J, Hagiwara A, Yamaguchi T, Sawai K, Takahashi T (1997) Overexpression of Bax sensitizes breast cancer MCF-7 cells to cisplatin and etoposide. Surgery Today 27: 676-679. DOI: 10.1007/BF02388231.

Salakou S, Kardamakis D, Tsamandas AC, Zolota V, Apostolakis E, Tzelepi V, Papathanasopoulos P, Bonikos DS, Papapetropoulos T, Petsas T, Dougenis D (2007) Increased $\mathrm{Bax} / \mathrm{Bcl}-2$ ratio up-regulates caspase-3 and increases apoptosis 
in the thymus of patients with myasthenia gravis. In vivo 21 : 123-32.

Tan C, Dlugosz PJ, Peng J, Zhang Z, Lapolla SM, Plafker SM, Andrews DW, Lin J (2006) Auto-activation of the apoptosis protein Bax increases mitochondrial membrane permeability and is inhibited by Bcl-2. The Journal of Biological Chemistry 281:14764-14775. doi: 10.1074/jbc.M602374200.

Wang ZQ, Liang S, Song-Ping W, Korotcov A, Xing-Jie L (2008) Transferrin Liposome Nanoparticle (TfNIR-LipNBD-
Magnevist)-A Tumor Targeting MRI Contrast Agent. Acta Biophysica Sinica 24:315-322.

Weinmann HJ, Brasch RC, Press WR, Wesbey GE (1984) Characteristics of gadolinium-DTPA complex: a potential NMR contrast agent. American Journal of Roentgenology 142:619-624. DOI: 10.2214/ajr.142.3.619.

Wray CJ, Ahmad SA, Matthews JB, Lowy AM (2005) Surgery for Pancreatic Cancer: Recent Controversies and Current Practice. Gastroenterological.128:1627-1647. DOI: http://dx.doi.org/10.1053/j.gastro.2005.03.035. 